\title{
建筑工程施工安全管理中BIM技术的有效运用
}

\author{
陈宝磊* \\ 绿地集团山东置业有限公司，山东 250000
}

\begin{abstract}
摘 要: 随着经济不断发展创新, 建筑工程领域得到前所未有的发展, 并在知识与经济互相融合的现代, 标志着 智能时代已经来临。在科学技术力量不断推崇下, BIM技术也得到了充分地使用, 并对施工安全管理方面的工作发挥 着重要力量, 为全面促进建筑施工安全管理贡献着重要作用。随着BIM技术的广泛普及, 促进了建筑工程领域的安全 管理。同时也在一定程度上保障了建筑工程施工的质量, 能够尽快实现科学强国的政策, 为群众提供更加完善的生活 空间。本文主要就BIM技术要点、BIM技术的广泛应用、BIM的优势进行分析。
\end{abstract}

关键词: BIM技术; 建筑工程；施工安全管理；有效运用

\section{Effective Application of BIM Technology in Construction Safety Management of Building Engineering}

\author{
Bao-Lei Chen* \\ Greenland Group Shandong Real Estate Co., Ltd., Jinan 250000, Shandong, China
}

\begin{abstract}
With the continuous development and innovation of economy, the field of construction engineering has achieved unprecedented development. The integration of knowledge and economy indicates that the intelligent era has come. With the continuous development of science and technology, BIM technology has also been fully used, plays an important role in construction safety management, and plays an important role in comprehensively promoting construction safety management. With the wide popularization of BIM technology, it promotes the safety management in the field of construction engineering. At the same time, it also ensures the quality of construction engineering to a certain extent, can realize the policy of scientific power as soon as possible, and provide more perfect living space for the masses. This paper mainly analyzes the key points of BIM technology, the wide application of BIM technology and the advantages of BIM.
\end{abstract}

Keywords: BIM technology; Building engineering; Construction safety management; Effect application

\section{一、前言}

就现阶段的建筑工程施工来说, BIM技术为其提供了全新的发展道路, 并有效地推动了 BIM技术的广泛应用, 为 建筑工程施工安全管理工作提供了重要帮助。为保障在未来实践过程中BIM技术的充分应用, 能够更完善地解决建筑 工程施工安全问题 ${ }^{[1]}$ 。并在未来的过程中不断完善BIM技术, 为建筑工程施工领域开创更加美好的未来。BIM技术在 建筑工程领域的广泛应用, 逐渐被越来越多的领域所重视 ${ }^{[2]}$ 。从建筑工程施工的角度来说, BIM技术的充分融人更适 合现阶段的建筑工程发展。因此相关单位更应该重视BIM技术的优势, 并充分融人到建筑工程施工安全管理工作中, 为建筑工程施工问题开创全新的方向。

\section{二、BIM 技术在建筑施工安全管理中的优势}

(一) 可视性较强

建筑工程施工安全面积十分广泛, 并且涉及的范围较为广泛, 通过BIM技术可视性较强的特点能够建立三维建筑 信息模型, 以此来充分掌握各类型建筑物类型的信息, 在对施工问题进行准备之前能够充分地锁定准确的位置, 为施

*通讯作者: 陈宝否, 1987年6月, 男, 汉, 山东济南人, 现任绿地集团山东置业有限公司项目经理, 中级工程 师，本科。研究方向：工程项目管理。 
工人员提供更加全面的位置信息，有效地避免在施工过程中一些棘手的问题，保障建筑工程施工的安全问题 ${ }^{[3]}$ 。

（二）模拟化较强

模拟化主要是指建筑工程施工过程中, 在施工过程进行时能够通过科学合理的模拟, 提前进行预防防护工作, 全 面保证施工问题的安全性和有效性, 保障建筑工程施工问题的合理应用, 保障工程设施整体的安全与稳定, 为建筑施 工领域贡献重要的条件 ${ }^{[4]}$ 。最重要的是BIM技术能够充分模拟一些危险系数较高的工作，比如脚手架、深基坑工作等 等, 协助各施工单位能够在安全的状态下进行施工, 并协助各部门进行安全工作交底任务, 保障建筑施工的合理性。

(三) 结合性较强

为保障施工人员的施工效率, 建筑工程施工安全管理中的BIM技术能够充分借助VR技术工程虚拟现实系统 (如图 1所示）, 将BIM技术与VR互相结合当建筑施工人员佩戴上专业眼镜之后, 可以在虚拟的建筑过程中开始施工, 对于 危险性系数较高的动作, 可以通过VR直观的来感受建筑环境, 以此来保障施工人员的施工安全, 才能保障施工人员 的施工安全, 为建筑人员提供良好的施工环境, 同时也避免了一定的经济损失, 还能够实现安全教育的目标。

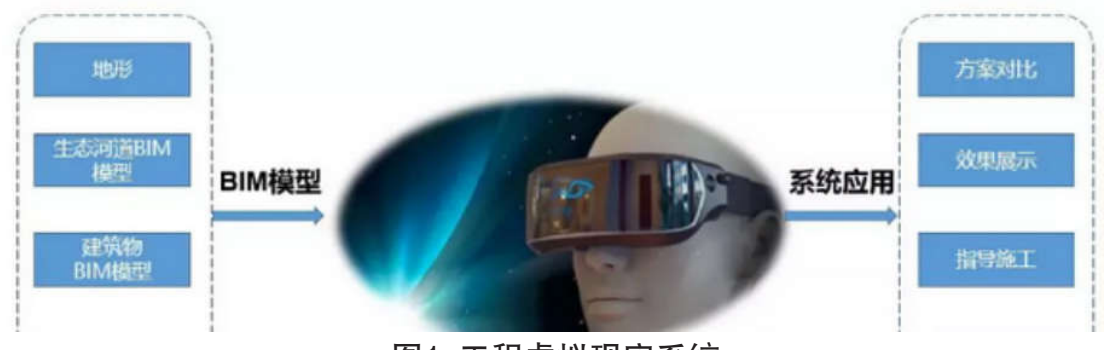

图1 工程虚拟现实系统

\section{三、BIM 技术在施工安全管理中存在的问题}

(一) 管理人员缺乏专业技术

在建筑工程施工过程中, 无论是哪一项工作都需要专业的管理人员进行管理, 也需要管理人员具备充足的BIM技 术管理经验, 但BIM技术作为新型建筑技术对于部分建筑团队来说尚未全面接收, 对于大部分的施工人员来说是一项 艰巨的任务, 只有高技术人员才能掌握部门BIM技术的应用方式, 一些传统施工理念较为坚固的施工人员难以全面适 应全新的技术，同时也对建筑施工工程带来了严重的困扰。

\section{(二) 缺乏BIM安全管理设备}

现阶段建筑领域虽然取得了良好的发展前景, 但建筑施工的安全问题却未得到全面的重视, 由于缺少BIM安全管 理设备, 在一定程度上导致安全管理人员的工作技能和安全水平远不足发到国家的水平 ${ }^{[5]}$ 。现阶段BIM安全管理的问 题不仅仅是人员素质较低的原因, 更需要充足的、完善的BIM安全管理设备作为支持, 也无从体现BIM技术在建筑工 程领域最大的价值，与建筑发展的实际需求并不相符，也对建筑施工管理工作带来一定的难度。

\section{四、建筑施工安全管理工作中 BIM 技术的广泛应用}

(一) 创建安全指标、充分应用BIM技术

为尽快实现BIM技术在建筑工程范围中的广泛应用, 在施工之前应充分借助数据进行合理地分析, 以此来保障建 筑施工技术的安全性 ${ }^{[6]}$ 。同时也应该通过建筑施工安全的周期性监理进行更加科学的指标管理, 以此来确定BIM技术 的施工安全问题, 并根据建筑施工标准并充分结合实践操作水平, 建立安全施工的指标来充分体现BIM技术在建筑工 程管理中的应用，保障工程项目安全进行。如图2所示是BIM工作流程图。

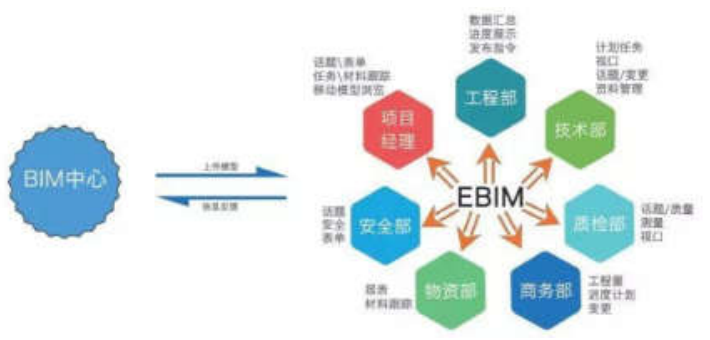

图2 BIM工作流程图 
（二）建立施工安全防护性能、创造良好的建筑环境

为保障建筑施工领域的稳定性，在项目进行施工之前应充分借助BIM技术来确保施工的防护性，这直接影响建筑 工程领域的有效进行，也间接性地影响了施工现场的安全问题，以至于造成更多的安全隐患问题。在BIM技术的充分 影响下, 相关部门能够高效地完成工作任务 ${ }^{[7]}$ 。因此相关部门应在对各项指标进行评估的过程中, 对施工现场进行合 理地设定与管理，为建筑施工领域营造良好的施工环境。

\section{（三）重视施工检查环节}

BIM技术在建筑工程中的应用, 不仅模拟化程度较强, 也需要强化对施工环节的检查任务, 确保施工环节的防护 性也是十分重要的工作内容, 在一定程度上影响了施工现场的安全问题, 因此在BIM技术简单的操作任务中能够快速 地完成工作任务, 在充分考虑影响因素的前提下, 逐渐完善对施工现场进行安全管理的设定标准 ${ }^{[8]}$ 。随着模拟化程度 的不断加强, 也意味着建筑工程领域的高层建筑进行模拟检查, 并在模拟的整体情况下, 应根据高层的情况对施工进 行安全的判断, 专业人员通过对模型的收集与模拟, 能够根据实际情况来分析进而排除安全隐患, 保障建筑工程领域 的稳定发展。专业人员通过对详细数据的收集, 应充分根据具体情况进行分析, 需要施工人员有效地解决安全隐患, 并为高层工组人员的施工带来安全保障。如图3所示是BIM技术支持各平台工作示意图。

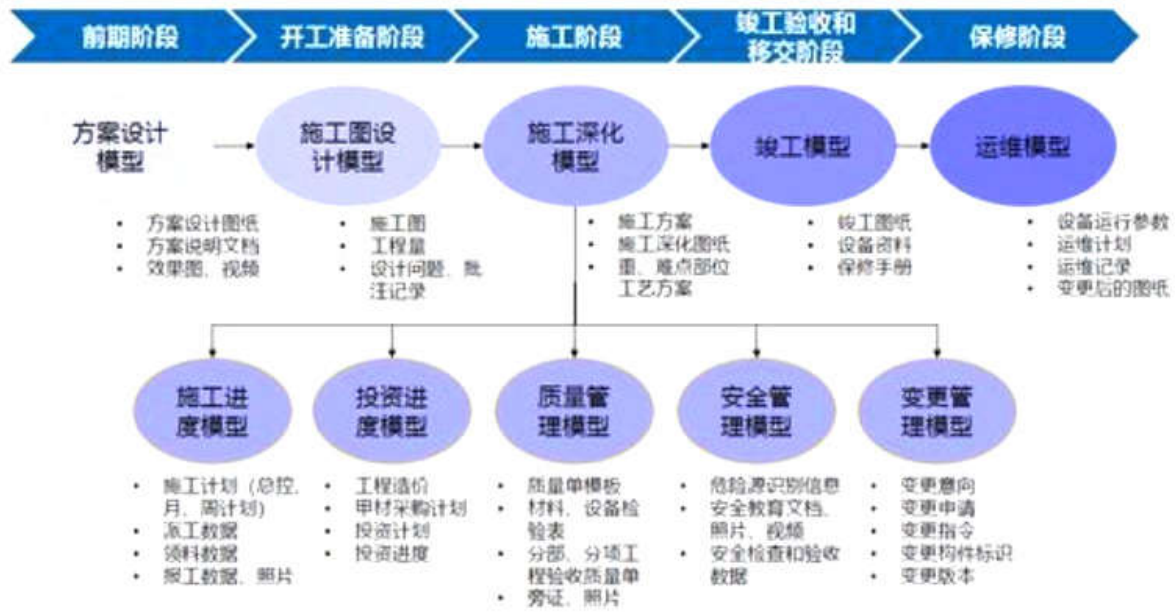

图3 BIM技术支持各平台工作示意图

（四）严格把控施工质量

在进行建筑施安全管理工作时，充分应用BIM技术能够改善建筑工程现场的问题，从现场的施工质量再到现场技 术的应用, 逐渐提升建筑工程的安全性管理。另外BIM技术需要全面依靠专业的设备进行支持, 为全面提升建筑工 程的安全性, BIM技术需要依托更加全面且专业的操作设备, 当施工现场出现安全问题时需能在第一时间解决安全问 题，为建筑施工提供良好的施工环境，并保障施工问题在第一时间进行发现并解决。

（五）借助BIM技术进行安全管理培训

在建筑工程施工当中应充分借助BIM技术来进行安全问题的管理工作，充分结束BIM技术对施工人员进行培训， 能够全面提升建筑施工的安全性, 保障BIM施工人员具备更加强烈的安全意识 ${ }^{[9]}$ 。应充分结合施工人员的个人意愿, 对建筑施工领域进行全面多样化的培训工作, 使建筑施工人员更加愿意接受类似的安全工作培训, 及时缓解建筑施工 当中的安全问题。

\section{五、结束语}

随着建筑工程领域的不断发展，BIM技术的全面应用给建筑领域带来了更加广泛的发展空间，也为在日后的实践 道路工作当中, 充分推广BIM技术在建筑工程领域的全面应用, 逐渐完善建筑施工中存在的问题, 为建筑领域提供更 加美好的发展未来。

\section{参考文献:}

[1]徐进,姜武.BIM技术在建筑工程安全管理中的应用研究[J].风景名胜, 2021(2):219.

[2]王朝民.BIM技术在建筑工程施工安全管理中的应用[J].建材发展导向(上), 2021,19(1):140-141. 
[3]刘峰.BIM技术在建筑工程安全管理中的应用研究[J].建筑与装饰, 2021(8): 145 .

[4]赵爽.建筑工程项目参与方BIM采纳影响因素及应对策略[J].建筑经济, 2021,42(3):51-54.

[5]谢存仁,徐峰,阮敏浩.基于BIM与遗传算法的建筑工程施工进度多目标优化研究[J].工程管理学报, 2021,35(3):117-122.

[6]高荣龙,许曾峰,王尧, 林斌, 郑堌阳.基于BIM的建筑工程施工项目成本控制与动态分析研究 [J]. 粉煤灰综合利用, 2021,35(3):137-140.

[7]陈丽娟,陆亚.BIM技术在地震灾后重建房屋建筑工程造价控制方法中的研究[J].地震工程学报, 2019,41(1):239-244.

[8]王雁.基于BIM的地震灾后民用建筑重建工程施工成本控制方法 [J].地震工程学报, 2019,41(1):233-238.

[9]刘镇.高职建筑工程技术专业课程体系的构建——基于“互联网+BIM”的背景[J].辽宁高职学报, 2019,21(3):60-63. 